Check for updates

Cite this: RSC Adv., 2017, 7, 35613

\title{
Photocatalytic alginate fuel cells for energy production and refining of macroalgae $\dagger$
}

\author{
Joyotu Mazumder, ${ }^{a}$ Hiroyuki Yoshikawa, (D) *ab Hideo Miyake, ${ }^{\text {bc }}$ Toshiyuki Shibata $^{\text {bc }}$ \\ and Eiichi Tamiya ${ }^{a}$
}

Using unused biomass, such as inedible brown macroalgae, as an alternative energy and chemical feedstock is important because these materials are cultivated easily and do not compete with food products. In this study, carbon electrodes modified with titanium dioxide $\left(\mathrm{TiO}_{2}\right)$ were fabricated and utilized for the photocatalyzed electrochemical oxidation of alginate, a structural polymer derived from brown macroalgae. A prototype fuel cell comprising a $\mathrm{TiO}_{2}$-modified carbon sheet $\left(\mathrm{TiO}_{2} / \mathrm{C}\right)$ electrode immersed in an alkaline solution containing $0.2 \%(\mathrm{w} / \mathrm{v})$ alginate was irradiated with artificial solar light, yielding a maximum power output of $81 \mu \mathrm{W} \mathrm{cm}$-2 at an irradiation intensity of $150 \mathrm{~mW} \mathrm{~cm}{ }^{-2}$. Furthermore, optical absorption and high-performance liquid chromatography analyses of the alginate solution after continuous fuel cell operation for $24 \mathrm{~h}$ showed that (1) artificial solar irradiation of the $\mathrm{TiO}_{2} / \mathrm{C}$ anodes enhances the oxidation of alginate to generate species with $\mathrm{C}=\mathrm{O}$ groups and (2) the generated species include those of lower molecular weights compared to those of the alginate polymer, possibly comparable to that of the constituent monomer unit of alginate. These results suggest that the oxidation pathway includes glycosidic bond cleavage of the alginate polymer chain in a manner similar to alginate oxidation using much harsher oxidizing agents.

Received 15th May 2017
Accepted 11th July 2017
DOI: 10.1039/c7ra05473d
rsc.li/rsc-advances

\section{Introduction}

With the rise of developing economies around the world, the consumption and demand for primary energy, which includes resources such as fossil and nuclear fuels (non-renewable), as well as energy from the sun and the wind (renewable), have increased dramatically. Although technological advances have allowed us to exploit vast and previously untapped reserves of fossil fuels, such as shale oil and gas, the depletion of these reserves continues. On the other hand, rising greenhouse gas emissions from the combustion of fossil fuels present another grave concern because of their contribution to global warming and the resultant increase in natural disasters.

To combat these concerns, people have increasingly looked to renewable and alternative energy sources, among them biomass. Because $\mathrm{CO}_{2}$ released during biomass combustion can be utilized for the cultivation of new plant matter, biomass is more carbon neutral than fossil fuels. In addition, biomass has

${ }^{a}$ Department of Applied Physics, Osaka University, 2-1 Yamada-oka, Suita, Osaka 565-0871, Japan. E-mail: yosikawa@ap.eng.osaka-u.ac.jp

${ }^{b} J S T$, CREST, 2-1 Yamadaoka, Suita, Osaka 565-0871, Japan

${ }^{c}$ Department of Life Science, Graduate School of Bioresources, Mie University, 1577 Kurimamachiya, Tsu, Mie 514-8507, Japan

$\dagger$ Electronic supplementary information (ESI) available: Additional details on the fabrication procedure of $\mathrm{TiO}_{2}$-modified anodes, output voltage measurement over $24 \mathrm{~h}$ operation, the HPLC analysis of alginate solutions, and Raman analysis of anodes. See DOI: 10.1039/c7ra05473d the potential to be used as a feedstock for many basic chemicals in a process known as biorefining, analogous to petrochemical refining, which produces chemicals ubiquitous in industrial and consumer products. ${ }^{1,2}$ However, most sources of biomass used currently, such as sugarcane and corn, would otherwise be used as food; thus, their use as fuel increases crop prices, limiting the use of these fuel sources. As such, much attention has been given to the utilization of inedible and currently unused biomass, including waste wood, sugarcane bagasse, and sewage sludge. ${ }^{\mathbf{1 , 3 - 5}}$

Solar energy is another renewable resource, whose applications have been researched extensively over the past decades. Photovoltaic cells (i.e., solar panels) based on semiconductor technology have undergone much development and become relatively commonplace in recent years, although significant efforts are still being made to develop cheaper, more efficient, and more robust devices. However, other systems aimed at converting solar energy to other forms, including solar electrolysis and photo-fuel-cells, are still in their nascent stages and have yet to be applied to practical situations. ${ }^{6,7}$

This investigation focuses on the use of biomass derived from inedible brown macroalgae, which grows in abundant quantities in the ocean and does not require fertilizer or arable land. The potential applications of alginate, a polysaccharide comprising a large fraction of the structural makeup of macroalgae, have prompted researchers to attempt its degradation, for example, by enzymatic treatment with engineered microbes, acid treatment, 
and gamma irradiation. ${ }^{8-12}$ However, these methods are expensive and energy intensive, which renders biofuel production from alginate impractical. We have previously attempted to oxidize alginate using a fuel cell setup with anodes modified with carbon nanotubes and gold nanoparticles, the latter of which exhibits catalytic activity towards glucose oxidation under alkaline conditions. ${ }^{13}$ We achieved limited success with this setup, partially oxidizing alginate and extracting energy in the process, albeit with low efficiency and a maximum power output of $5.6 \mu \mathrm{W}$ $\mathrm{cm}^{-2}$. This low efficiency is attributed to the stable structure of alginate, which results in its resistance to oxidation, as well as the possible poisoning of the catalytic gold nanoparticles during fuel cell operation. In this study, we utilized $\mathrm{TiO}_{2}$ as the anode photocatalyst in place of carbon nanotubes and gold nanoparticles to improve upon our previous work and enhance the oxidation of alginate during fuel cell operation.

\section{Experimental}

Throughout this work, $\mathrm{TiO}_{2} / \mathrm{C}$ anodes were fabricated by directly depositing $\mathrm{TiO}_{2}$ nanoparticles (Ishihara Sangyo, STS-21, average particle size: $\sim 20 \mathrm{~nm}$ ) dispersed in methanol onto carbon sheet (TOSHIMA Manufacturing Co., Ltd.) substrates, followed by annealing. This resulted in the immobilization of $\mathrm{TiO}_{2}$ on the substrates without the use of other supporting materials and enabled the facile preparation of the anodes. The anodes used in this setup had sizes of $2 \times 1 \mathrm{~cm}$, meaning that, to achieve a $\mathrm{TiO}_{2}$ loading of $1 \mathrm{mg} \mathrm{cm}{ }^{-2}$, we required $50 \mu \mathrm{L}$ of a $5 \mathrm{mg} \mathrm{mL}^{-1}$ dispersion of $\mathrm{TiO}_{2}$ particles in methanol, and this was dropped a total of eight times onto the anode surface before annealing. Scanning electron microscope (SEM) images of the fabricated anode (Fig. 1a) show that the $\mathrm{TiO}_{2}$ nanoparticles are immobilized with a dense distribution on the surface. Further details of the general anode fabrication procedure are provided in the ESI. $\dagger$

The prototype fuel cell was assembled using a commercial $\mathrm{H}$ type electrochemical cell (EC Frontier, VB9) with the anode and alginate solution $(12 \mathrm{~mL}$ of $0.2 \%(\mathrm{w} / \mathrm{v})$ sodium alginate in $0.5 \mathrm{M}$ $\mathrm{NaOH}$ ) contained in one compartment, while a Nafion cationexchange membrane and platinum mesh cathode were sandwiched between the two compartments (Fig. 1b).

Polarization (current-voltage, $I-V$ ) curves were measured by a digital electrometer R8240 (Advantest). To evaluate the longterm operation, we measured the fuel cell voltage continuously over a period of $24 \mathrm{~h}$. Detailed measurement steps are described in the ESI. $\dagger$

For the artificial solar irradiation of the anodes, a solar simulator (Asahi Spectra, HAL-320) containing a $300 \mathrm{~W}$ xenon lamp was used. For subsequent experiments, the power output of the solar simulator and its distance to the fuel cell were adjusted so that the irradiation intensity at the point of incidence on the cell was 1.5 suns $\left(150 \mathrm{~mW} \mathrm{~cm}^{-2}\right)$.

\section{Results and discussion}

\subsection{Evaluation of the $\mathrm{TiO}_{2} / \mathrm{C}$ anodes and alginate fuel cells}

To evaluate the nanostructure and crystallinity of $\mathrm{TiO}_{2}$ on an anode, transmission electron microscopy was performed. $\mathrm{TiO}_{2}$

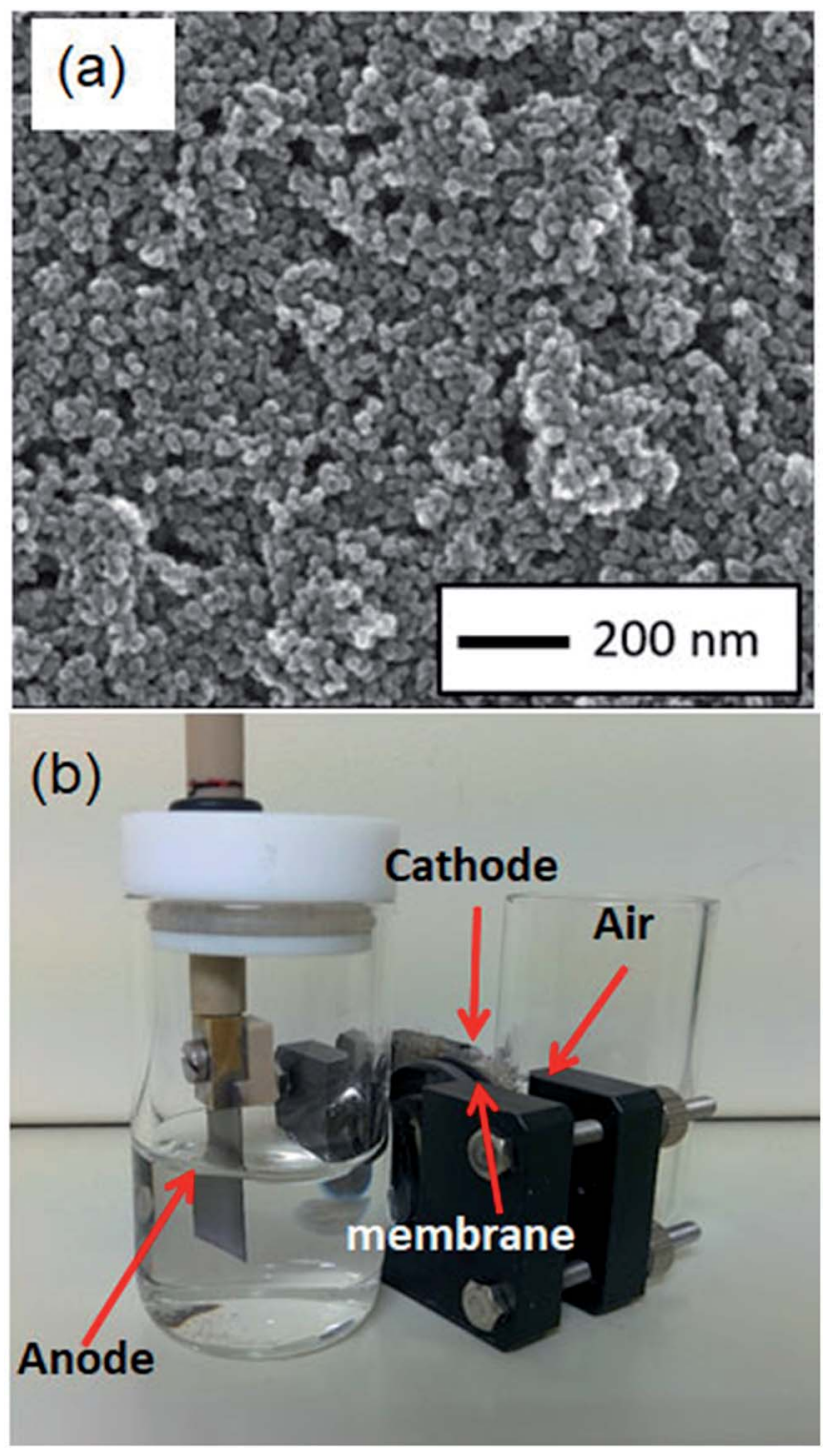

Fig. 1 (a) SEM image of a $\mathrm{TiO}_{2} / \mathrm{C}$ anode. (b) Photo of an alginate fuel cell.

on an anode was scraped off and deposited on a TEM grid. TEM (Hitachi, H-800) was operated at an accelerating voltage of 200 $\mathrm{kV}$. The TEM image (Fig. 2a) demonstrates that small $(\sim 20 \mathrm{~nm})$ nanoparticles aggregate without fusing to each other. This indicates that nanoporous structures are formed between nanoparticles. Fig. 2b shows the electron diffraction pattern measured by the TEM. Diffraction rings are in good agreement with the anatase phase of $\mathrm{TiO}_{2}$ in JCPDS file no 21-1272. The crystallinity of $\mathrm{TiO}_{2}$ on the anode was also confirmed by Raman spectroscopy. The Raman spectrum was measured by a Raman spectrometer (Hamamatsu, C12710) with a laser excitation wavelength of $785 \mathrm{~nm}$. Fig. 2c shows the Raman spectrum of the surface of the fabricated $\mathrm{TiO}_{2} / \mathrm{C}$ anodes. The spectrum contains several peaks: a sharp peak at $1578 \mathrm{~cm}^{-1}$ and a smaller, broad peak at $1312 \mathrm{~cm}^{-1}$. The former peak is known as the $\mathrm{G}$ band, which is attributed to $\mathrm{sp}^{2}$-hybridized carbon-carbon bonds common to graphene and other structures comprised of hexagonal carbon atom networks. The latter peak, known as the 


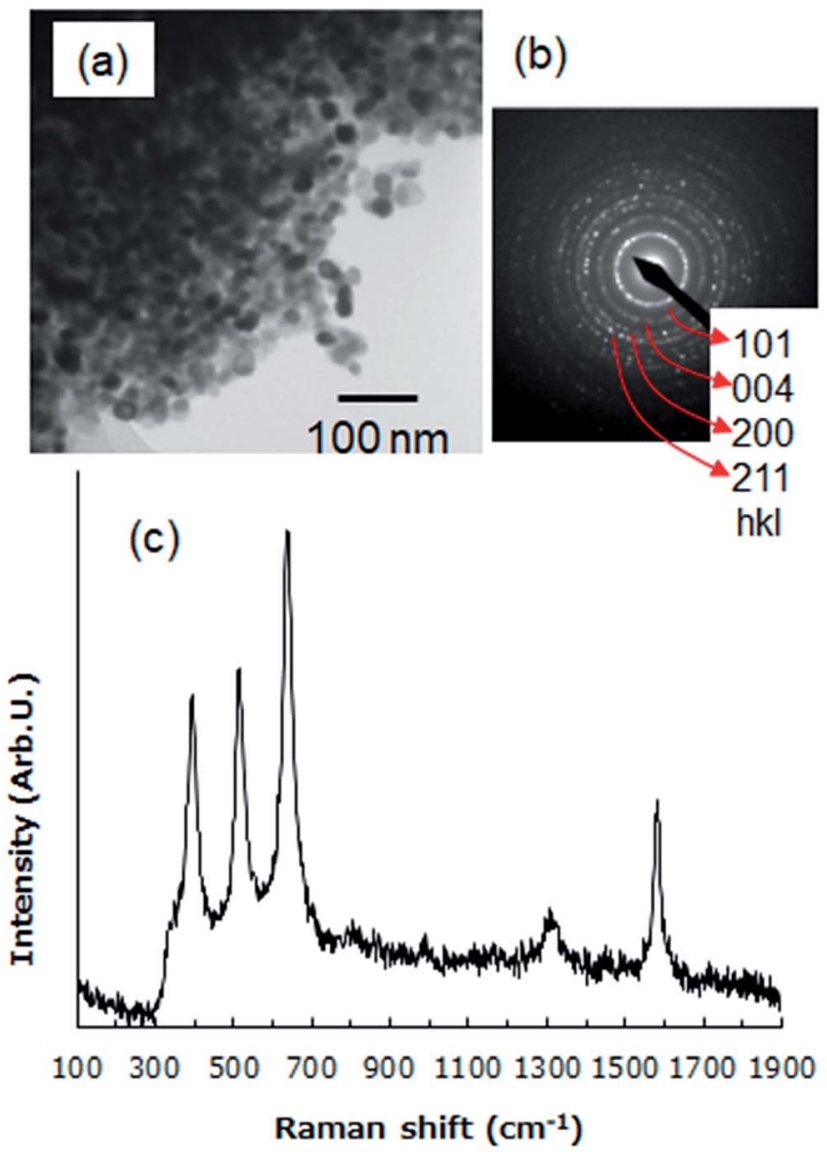

Fig. 2 (a) TEM image and (b) electron diffraction pattern of $\mathrm{TiO}_{2}$ on an

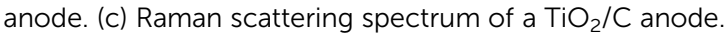

$\mathrm{D}$ band, is attributed to $\mathrm{sp}^{3}$-hybridized carbon-carbon bonds and dangling bonds seen in less ordered carbon structures. ${ }^{14}$ In addition, Raman bands at approximately 395, 514, and 638 $\mathrm{cm}^{-1}$ correspond to the $\mathrm{B}_{1 \mathrm{~g}}$ (symmetric bending of $\mathrm{O}-\mathrm{Ti}-\mathrm{O}$ ), $\mathrm{A}_{1 \mathrm{~g}}$ (antisymmetric bending of $\mathrm{O}-\mathrm{Ti}-\mathrm{O}$ ), and $\mathrm{E}_{\mathrm{g}}$ (symmetric stretching of $\mathrm{O}-\mathrm{Ti}-\mathrm{O}$ ) vibrational modes, respectively, of anatase $\mathrm{TiO}_{2} \cdot{ }^{15,16}$ These results demonstrate that $\mathrm{TiO}_{2}$ nanoparticles were immobilized on the anode while maintaining the original anatase structure, which has a higher photocatalytic activity than that of rutile.

Fig. 3 shows the polarization and power density curves of the fuel cell measured with and without artificial sunlight. A maximum power density of $31 \mu \mathrm{W} \mathrm{cm}{ }^{-2}$ was achieved without light illumination, 6 times higher than that obtained previously. ${ }^{13}$ Gold nanoparticles decorated on carbon nanotubes have previously been used as the anode material because gold is a good catalyst for the electrochemical oxidation of carbohydrates. Notably, $\mathrm{TiO}_{2}$ itself (without solar irradiation) is also a good catalyst for alginate oxidation. However, the maximum power density was improved by artificial solar irradiation. Fig. 3 shows that a power density of $81 \mu \mathrm{W} \mathrm{cm}{ }^{-2}$ was achieved at a current density of $160 \mu \mathrm{A} \mathrm{cm}^{-2}$ under the solar illumination of 1.5 suns. The sunlight boosts the power of the alginate fuel cell by the photocatalytic effect of $\mathrm{TiO}_{2}$. Previously, other groups

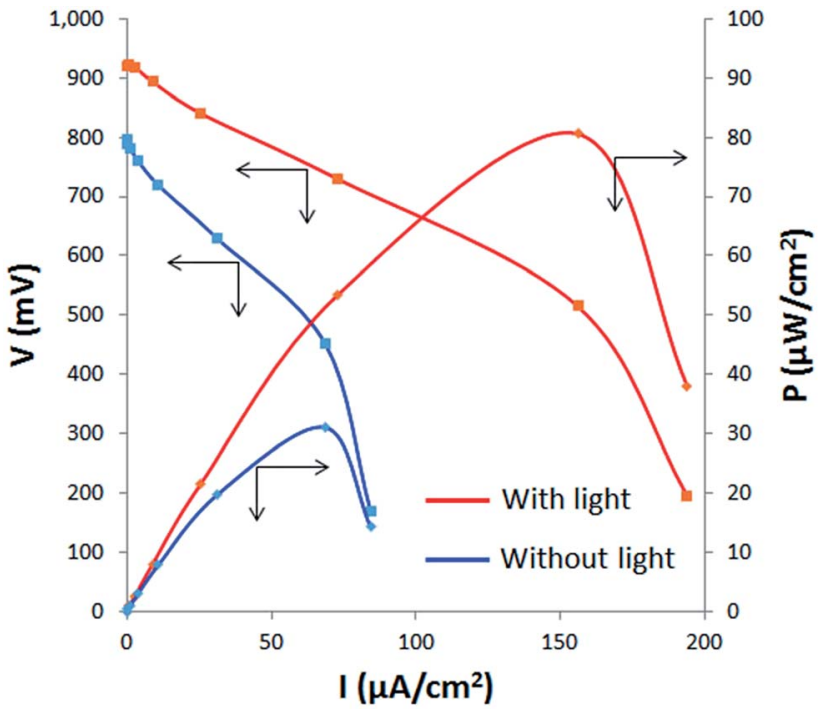

Fig. 3 Polarization and power density curves of the alginate fuel cell operated with (red lines) and without (blue lines) artificial solar irradiation on the anodes.

have reported the output enhancement of direct methanol or ethanol fuel cells by the photocatalytic effect. ${ }^{17-19}$ Kamat and coworkers reported that the power of methanol fuel cells with $\mathrm{TiO}_{2} / \mathrm{Pt}-\mathrm{Ru}$ anodes were enhanced by UV lamp irradiation. ${ }^{17} \mathrm{In}$ their case, the maximum intensity was increased from 700 to $900 \mu \mathrm{W} \mathrm{cm} \mathrm{cm}^{-2}$ by illumination from a $28 \mathrm{~mW} \mathrm{~cm}{ }^{-2} \mathrm{Hg}$ lamp. Li et al. fabricated methanol fuel cells with graphene- $\mathrm{TiO}_{2}$ nanorod anodes and confirmed $1.1 \mu \mathrm{W} \mathrm{cm}{ }^{-2}$ power generation by artificial solar irradiation at $60 \mathrm{~mW} \mathrm{~cm}{ }^{-2}(\sim 0.6$ suns $) .{ }^{18}$ These previous investigations have demonstrated the potential of combining fuel cells with photocatalytic effects. The basic mechanism of the power enhancement under the solar illumination could be common among our present study and previous studies by other groups. ${ }^{17,18}$ Briefly, $\mathrm{TiO}_{2}$ is excited by light (mainly UV) irradiation and electron-hole pairs are produced. Fuels (alginate, methanol, and so on) are oxidized by photogenerated holes, whereas photogenerated electrons are collected by carbon substrates and flow to the cathode through an external circuit. However, methanol and ethanol used in previous reports are inherently good fuel. Even without the solar assistance, a power density of more than a hundred milliwatts per square centimeter has been reported recently in a methanol fuel cell. ${ }^{20}$ In the present work, alginate has low reactivity toward electrochemical oxidation, and the use of photocatalytic reactions can improve this. The power enhancement caused by the light illumination is also clearly confirmed.

Not only the maximum power density but also long-term operational characteristics and stability were improved by solar illumination. Thus, to assess these more accurately, the temporal change in the output voltage of the fuel cell was measured via a $3.3 \mathrm{k} \Omega$ load resistance, as shown in Fig. 4. The output steeply decreased in the first few hours either with or without solar illumination. We need further analysis to investigate and improve this rapid output decline. After a few hours, 


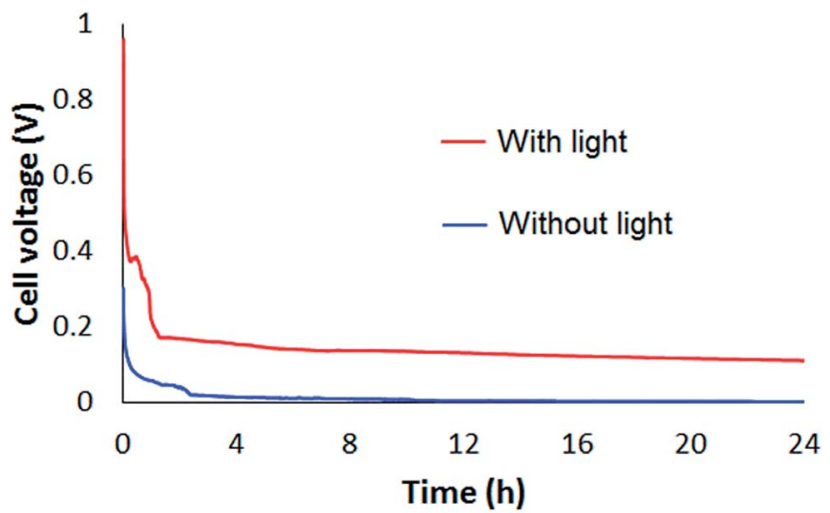

Fig. 4 Voltage vs. time plots of fuel cell performance over $24 \mathrm{~h}$ operation with (red line) and without (blue line) artificial solar irradiation of the anodes.

the output decreased to near $0 \mathrm{~V}$ without solar illumination. However, the output was level over the $24 \mathrm{~h}$ operation under solar illumination. Although the cell voltages decreased with time, the rates of decrease slowed, and the final cell voltage was higher than those without solar irradiation. These results indicate that photocatalysis by light-irradiated $\mathrm{TiO}_{2}$ has one or several of the following effects: increased alginate oxidation, delayed surface poisoning through self-cleaning, and improved charge transfer to the external circuit. Photocatalytic $\mathrm{TiO}_{2}$ is commonly used as a self-cleaning coating, where hydroxyl radicals generated by exposure to light decompose molecules adsorbed on the $\mathrm{TiO}_{2}$ surface. In general, poisoning is mainly caused by $\mathrm{CO}$ adsorption on catalysts of anodes. ${ }^{17}$ We performed Raman spectroscopy to evaluate poisoning and selfcleaning effect. Raman spectral shape of a $\mathrm{TiO}_{2} / \mathrm{C}$ anode showed a characteristic broad band after $24 \mathrm{~h}$ operation without solar, whereas it kept the original shape under the solar illumination as shown in Fig. S2 in ESI. $\uparrow$ These experimental results indicate that the cleaning effect of $\mathrm{TiO}_{2}$ contributes to the enhancement of the output voltage during long-term operation.

The coulombic efficiency of the electrochemical oxidation of alginate during $24 \mathrm{~h}$ operation of the fuel cell was estimated from Fig. 4. The number of electrons released, $N$, was obtained from the total charge, $Q$, which was calculated by integrating the current over $24 \mathrm{~h}$, divided by the value of the elementary charge $\left(1.602 \times 10^{-19} \mathrm{C}\right)$. The total number of electrons available in the alginate in the solution was estimated based on the proposed oxidation mechanism of alginate. We assumed that two electrons were released for every oxidized monomer unit of alginate. Because $12 \mathrm{~mL}$ of a $0.2 \%(\mathrm{w} / \mathrm{v})$ alginate solution was used, $24 \mathrm{mg}$ of sodium alginate was present in the solution. Using the molecular weight of the monomer units $\left(\mathrm{C}_{6} \mathrm{H}_{7} \mathrm{O}_{6} \mathrm{Na}=198\right)$ and Avogadro's number $\left(N_{\mathrm{A}}=6.022 \times 10^{23}\right)$, the total number electrons in the solution available for release $N_{0}$ is given by $2 \times$ $\left(7.3 \times 10^{19}\right)=14.6 \times 10^{19}$. Fig. 4 indicates that only $0.5 \%$ of the available electrons were used for oxidation in the absence of solar light, whereas this value increased to $7.9 \%$ in the presence of solar illumination. Although this value is still low compared to those of other biomass fuel cells, the photocatalytic reaction increased the oxidation efficiency of the alginate fuel cell to a practical level. ${ }^{21,22}$ This result indicates that the photocatalytic effect becomes more prominent as the fuel cell operates for longer time.

\subsection{Analysis of the fuel cell reaction products}

The above experimental results demonstrate that the photoelectrochemical fuel cell can oxidize alginate efficiently. To gain some insight into the nature of the alginate oxidation products obtained through fuel cell operation, we analyzed, using UV-vis absorption spectroscopy, the used alginate solutions following $24 \mathrm{~h}$ continuous fuel cell voltage measurements. Fig. 5 shows the obtained absorption spectra of the solutions after $24 \mathrm{~h}$ operation of the fuel cell with and without artificial solar irradiation. While the solutions after $24 \mathrm{~h}$ operations, both with and without artificial solar irradiation, show absorption in the ultraviolet range, there is a peak at approximately $265 \mathrm{~nm}$ for the irradiated solution that is not present in the unirradiated solution. This absorption peak is ascribed to the $n \rightarrow \pi^{*}$ transition of carbonyl groups $(\mathrm{C}=\mathrm{O})$ and corresponds to alginate degraded by gamma irradiation. ${ }^{12}$ This indicates that artificial solar irradiation of $\mathrm{TiO}_{2} / \mathrm{C}$ anodes enhances alginate oxidation, and results in the generation of $\mathrm{C}=\mathrm{O}$ bonds. In previous reports concerning alginate degradation, two oxidation pathways have been demonstrated. One involves the cleavage of the glycosidic bonds connecting adjacent monomers, splitting the polymer chain into shorter chains. The other pathway involves the cleavage of $\mathrm{C}-\mathrm{C}$ bonds within a monomer ring. What is common between these two pathways is that they result in the formation of new carbonyl $(\mathrm{C}=\mathrm{O})$ bonds. The carbonyl bond has a characteristic absorption peak, as shown in Fig. 5. However, the former pathway results in a decrease in the molecular weight. In the previous report on the alginate fuel cell, the oxidation pathway was likely the latter because no reduction in the molecular weight of the alginate fuel was observed. $^{13}$

The oxidized solutions were analyzed by size-exclusion highperformance liquid chromatography (HPLC) to determine

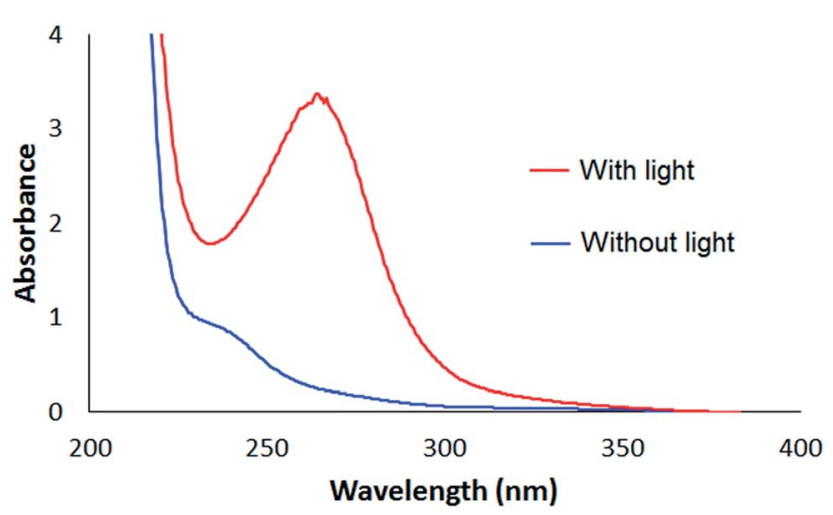

Fig. 5 Absorption spectra of the alginate solutions after $24 \mathrm{~h}$ operation with (red line) and without (blue line) artificial solar irradiation of the anodes. 
whether alginate oxidation through the irradiation of the $\mathrm{TiO}_{2} /$ $\mathrm{C}$ anodes resulted in the production of lower molecular weight species. Size-exclusion chromatography makes use of column packing agents with numerous pores that retain smaller molecules for longer periods of time compared to larger ones. This enables the determination of relative size differences among the species present in a sample (or absolute sizes if a calibration curve using molecular weight standards of appropriate sizes is created). The HPLC curve of the alginate solution before fuel cell operation was determined using a refractive index difference (RID) detector (blue line in Fig. 6). This indicates that the main peak around $11.6 \mathrm{~min}$ (blue line) is attributed to alginate. After fuel cell operation with solar illumination (red line in Fig. 6), the area of this peak was diminished. In addition, a new peak was present in the chromatograms of these solutions at around $14.8 \mathrm{~min}$, which is absent in that of the solution before the $24 \mathrm{~h}$ long measurement. This new peak, together with the reduction in the primary alginate peak, suggest the generation of lower molecular weight species through alginate oxidation. The reduction in the alginate peak is larger than the coulombic efficiency $(7.9 \%)$ estimated in the former section from Fig. 4. This is reasonable because some electrons do not flow to the cathode and could have been consumed for other chemical reactions in solution.

To focus on the products detected by the absorption spectral measurements (Fig. 5), we carried out HPLC in concert with UV absorbance measurements at $260 \mathrm{~nm}$ (Fig. 7). The signal intensity of original solution (blue line) is quite low. The peak at around 11.4 minutes is attributed to the alginate. Fig. 7 shows the multiple prominent peaks in the chromatogram of the solution after $24 \mathrm{~h}$ operation with artificial solar irradiation (red line). The species responsible for these peaks are likely the same as those that produced the large absorption peak at around $260 \mathrm{~nm}$ in Fig. 5.

Previously, we compared the sizes of the species to those of pullulan molecular weight standards (Shodex) under the same conditions. ${ }^{13}$ The standard sample P-5, which is the smallest pullulan standard available $(\sim 5900)$, appeared at a retention time of approximately $13 \mathrm{~min}$. Species that appear at later retention times have lower molecular weights; thus, to assess

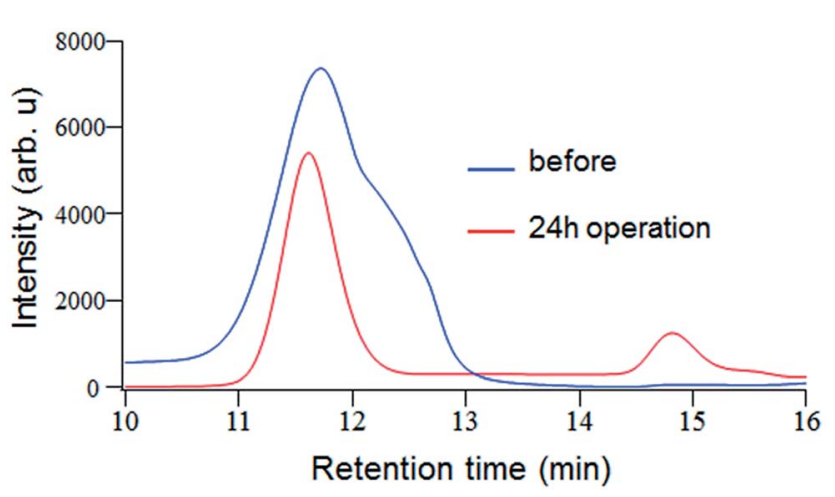

Fig. 6 Chromatograms of the alginate solutions measured using an RID detector before (blue line) and after (red line) $24 \mathrm{~h}$ operation with artificial solar irradiation of the anodes.

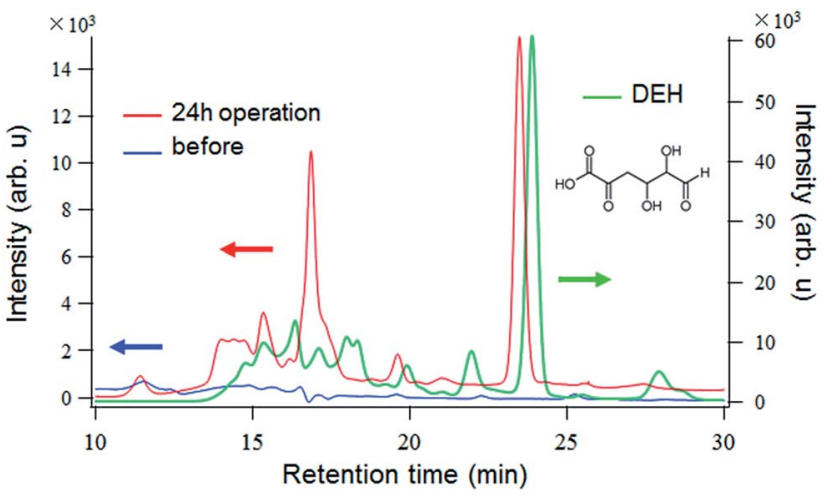

Fig. 7 Chromatograms of the alginate solutions measured using a UV absorbance detector before (blue line) and after (red line) $24 \mathrm{~h}$ operation with artificial solar irradiation of the anodes.

the size of the species produced, another standard sample must be used. To this end, a monosaccharide produced by the enzymatic breakdown of alginate, 4-deoxy-L-erythro-5-hexoseulose uronic acid (DEH, Fig. 7 inset), was dissolved in water and analyzed by HPLC under the same conditions. Chromatograms based on the UV detector output could be used for comparison because DEH also has a carbonyl group, which absorbs light at around $260 \mathrm{~nm}$. The obtained chromatograms for DEH and that of the alginate after $24 \mathrm{~h}$ artificial solar irradiation are shown together in Fig. 7. The chromatogram of DEH shows multiple signals and a prominent peak at around $24 \mathrm{~min}$. The cause of the earlier and less intense signals is unclear, but it is possible that they are due to residual intermediates and substances left behind from the isolation of DEH from the post-enzymatic reaction mixture. Based on the high intensity of the peak at 24 min, it is likely DEH. Interestingly, this peak is near the primary peak in the oxidized alginate solution, and the two peaks are separated by less than 1 min elution time. Thus, it is possible that the oxidation of alginate with the $\mathrm{TiO}_{2} / \mathrm{C}$ anodes after $24 \mathrm{~h}$ fuel cell operation under artificial solar irradiation cleaves the glycosidic bonds linking adjacent monomer units to produce smaller substances with lower molecular weights that are similar to, if not the same as, the monomers themselves.

\section{Conclusions}

This work explored the prospects of the biorefinery of polysaccharides derived from inedible brown macroalgae through photo-electrochemical oxidation in alginate fuel cells comprising photocatalyst-modified anodes. Titanium dioxidemodified carbon sheet $\left(\mathrm{TiO}_{2} / \mathrm{C}\right)$ anodes were fabricated and applied to use in direct alginate fuel cells. The operational characteristics and long-term stability of these fuel cells under the absence and presence of artificial solar irradiation, and the products generated by the operation of fuel cells, were investigated. A maximum power density of $81 \mu \mathrm{W} \mathrm{cm} \mathrm{cm}^{-2}$ was achieved under artificial solar irradiation at an intensity of $150 \mu \mathrm{W} \mathrm{cm}$. In addition, $7.9 \%$ of the total alginate in solution was oxidized after 24 hour fuel cell operation due to the long-term stability. 
These experimental results demonstrate the current alginate fuel cell's extremely high performance as compared to that without photocatalytic materials in the previous report. In addition, optical absorption and HPLC analyses of the alginate solution after 24 hour continuous fuel cell operation showed that the generated species include those of lower molecular weights comparable to that of the constituent monomer units of alginate, suggesting the oxidation pathway including glycosidic bond cleavage. The decomposition of polysaccharides (carbohydrates) is important for the biorefining of unused and inedible biomass. Although various decomposition procedures for alginate based on chemical reactions and radiation have been proposed, our alginate fuel cell is a safer and more ecological approach. Furthermore, electric power is generated. Further product analysis and the scale-up of these systems remains a challenge for practical application. Electrochemical and photochemical analyses with radical-trapping reagents are also necessary to more deeply understand the reaction mechanisms involved. The design and development of an appropriate fuel cell and cell stack configurations, as well as procedures for the fabrication of large-scale catalyst-modified electrodes, will be the keys to driving biomass refining using fuel cells.

\section{Acknowledgements}

This work was supported by JST, CREST. We thank Kosuke Takimoto at Advantec Co., Ltd. for assisting with the HPLC analysis. The authors acknowledge to Dr Eiji Taguchi in research center for ultra-high voltage electron microscopy in Osaka University for the support of TEM experiments.

\section{References}

1 B. Kamm and M. Kamm, Appl. Microbiol. Biotechnol., 2004, 64, 137.

2 Y. Sugano, T. Saloranta, J. Bobacka and A. Ivaska, Phys. Chem. Chem. Phys., 2015, 17, 11609.

3 D. Tilman, J. Hill and C. Lehman, Science, 2006, 314, 1598. 4 S. Kim and B. E. Dale, Biomass Bioenergy, 2004, 26, 361.

5 A. I. Rushdi, K. F. Al-Mutlaq, S. K. Sasmal and B. R. T. Simoneit, Fuel, 2013, 103, 970.
6 J. A. Herron, J. Kim, A. A. Upadhye, G. W. Huber and C. T. Maravelias, Energy Environ. Sci., 2015, 8, 126.

7 H. L. Tuller, Mater. Renew. Sustain. Energy, 2017, 6, 3.

8 A. J. Wargacki, E. Leonard, M. N. Win, D. D. Regitsky, C. N. Santos, P. B. Kim, S. R. Cooper, R. M. Raisner, A. Herman, A. B. Sivitz, A. Lakshmanaswamy, Y. Kashiyama, D. Baker and Y. Yoshikuni, Science, 2012, 335, 308.

9 T. Mori, M. Takahashi, R. Tanaka, H. Miyake, T. Shibata, S. Chow, K. Kuroda, M. Ueda and H. Takeyama, PLoS One, 2016, 11, e0155537.

10 H. Takeda, F. Yoneyama, S. Kawai, W. Hashimoto and K. Murata, Energy Environ. Sci., 2011, 4, 2575.

11 H. J. Lucas and W. T. Stewart, J. Am. Chem. Soc., 1940, 62, 1792.

12 L. Q. Luan, N. Nagasawa, V. T. T. Ha and T. M. Nakanishi, Radioisotopes, 2009, 58, 1.

13 L. Q. Hoa, H. Yoshikawa, M. Saito, M. Ueda, T. Shibata and E. Tamiya, ChemCatChem, 2014, 6, 135.

14 A. Jorio, E. H. Martins Ferreira, M. V. O. Moutinho, F. Stavale, C. A. Achete and R. B. Capaz, Phys. Status Solidi $B, 2010,247,2980$.

15 J. Yan, G. Wu, N. Guan, L. Li, Z. Li and X. Cao, Phys. Chem. Chem. Phys., 2013, 15, 10978.

16 F. Tian, Y. Zhang, J. Zhang and C. Pan, J. Phys. Chem. C, 2012, 116, 7515.

17 K. Drew, G. Girishkumar, K. Vinodgopal and P. V. Kamat, J. Phys. Chem. B, 2005, 109, 11851.

18 X. Li, G. Wang, L. Jing, W. Ni, H. Yan, C. Chen and Y. M. Yan, Chem. Commun., 2016, 52, 2533.

19 L. Zhang, L. Bai, M. Xu, L. Han and S. Dong, Nano Energy, 2015, 11, 48 .

20 E. Antolini and E. R. Gonzalez, J. Power Sources, 2010, 195, 3431.

21 V. T. Huong, H. Yoshikawa, L. Q. Hoa, H. Toake, T. Shibata and E. Tamiya, J. Solid State Electrochem., 2016, 20, 1481.

22 D. Scott and B. Y. Liaw, Energy Environ. Sci., 2009, 2, 965. 